Vantage: Journal of Thematic Analysis

ISSN: 2582-7391

A Multidisciplinary Publication of Centre for Research, Maitreyi College, University of Delhi

October 2020, Volume 1, Issue 2

Review Article

\title{
Probable Strategies to Combat Corona Pandemic by Tracing its Re- Emergence from SARS Virus
}

\author{
Nikita Goel, Ritika and Sarita Kumari* \\ Department of Botany, Maitreyi College, University of Delhi \\ *Correspondence: skumari2@maitreyi.du.ac.in
}

\begin{abstract}
SARS-CoV-2 which is closely related to SARS-CoV is prevalent in humans and animals as it infects their respiratory system or gut lining. The minor emergence of SARS in late 2003 and the recent discovery of bat SARS-CoV, suggests that SARS can return if conditions are optimum to proliferate. The re-emergence has led to various researches on the basic scientific aspects of the disease. Hence, we aim to study the life cycle of the virus in the human host cell focusing on the key events which may lead to potential therapeutic strategies against COVID-19. We also aim to analyze the other SARS-CoV genome similarities with the SARS-CoV-2 genome. Another objective of this review is to deal with present-day Covid-19 which can be studied by determining the source of emergence and transmission of previously occurred SARS- CoV pandemic. We aim to deduce possible measures of controlling the epidemic by taking a cue from the various mitigation techniques of SARS and the analysis of epidemiology, infection cycle and pathogenicity.
\end{abstract}

KEYWORDS: SARS-CoV-2, SARS, COVID-19, Genome, Emergence, Transmission

\section{INTRODUCTION}

Coronaviruses (CoVs) belong to the family Coronaviridae which are enveloped singlestranded positive sense RNA viruses. Corona represents crown-like spikes on the outer surface of the virus thus it is named as a coronavirus. Four genera of coronaviruses i.e. Alphacoronavirus $(\alpha \mathrm{CoV})$, Betacoronavirus $(\beta \mathrm{CoV})$, Gammacoronavirus $(\gamma \mathrm{CoV})$ and Deltacoronavirus $(\delta \mathrm{CoV})$ are included in the subfamily Coronavirinae. This classification is based on the antigenic and genetic properties of coronaviruses. SARSCoV-2 belongs to the $2 \mathrm{~B}$ group of Betacoronavirus genera with a genomic size of $\sim 30$

Vantage: Journal of Thematic Analysis, 2020; 1(2): 21-45 
$\mathrm{kb}$ (Figure 1). It is mainly responsible to cause severe clinical respiratory syndromes like that of SARS-CoV and MERS-CoV. SARS-CoV-2 being a highly diffusible virus that spreads rapidly via both affected symptomatic and asymptomatic people. It is also known to spread via droplets shed by the affected person or by direct contact with infected objects. Previous epidemics such as SARS-CoV and MERS-CoV have proved that the coronavirus has the potency to cross species barriers in order to emerge rapidly in humans.

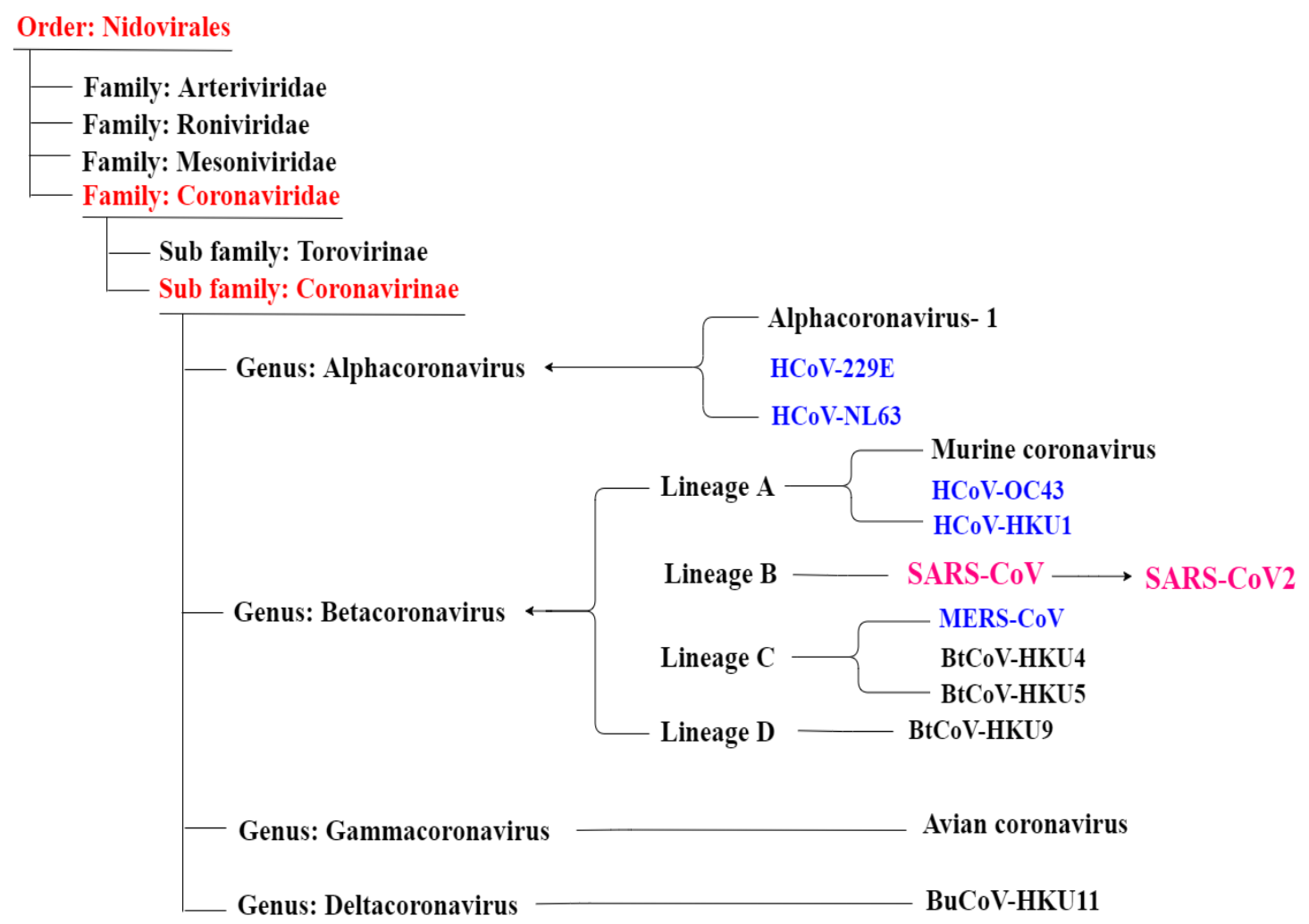

Figure 1: Classification of SARS-CoV and other coronaviruses (Yan et al., 2020)

The current COVID- 19 pandemic is unprecedented but the global response draws lessons learned from other disease outbreaks over the past several decades. Coronaviruses undergo genetic recombination very frequently, giving rise to new genotypes leading to other such outbreaks (Cheng et al., 2007). Lack of biosafety measures with the intermediate host also acting as a reservoir for the virus has allowed the outbreak of this pandemic. The diseases like SARS could reemerge in the near future and hence, the need for vigilance. Current knowledge regarding coronaviruses from a short history to epidemiology, pathogenesis, and clinical manifestations from the 
available literature can be used to draw possible treatment and prevention strategies. By studying the life cycle along with their possible inhibitors at various stages, this aim can be accomplished. These strategies, if found effective can be used, to combat the virus after the person is infected via drugs/vaccines before the infection. Future strategies that aim to prevent the recurrence of the pandemic are also discussed.

\section{RE-EMERGENCE AND EPIDEMIOLOGY OF CORONAVIRUS}

The first coronavirus infections were reported in the year 1960 as a cause for the common cold. Until the year 2002, only four subtypes of coronaviruses were reported to infect humans, two $\alpha$ coronaviruses (229E and NL63) and two $\beta$ coronaviruses (OC43 and HKU1), which routinely generate non-complicated infections of the upper and/or lower respiratory tract (Docea et al., 2020). Then, the first lethal Severe Acute Respiratory Syndrome (SARS) causing coronavirus emerged in the year 2002. The infected patients exhibited pneumonia-like symptoms with a diffuse alveolar injury which lead to Acute Respiratory Distress Syndrome (ARDS). Following the same, China faced an outbreak caused by a virus that caused Severe Acute Respiratory Syndrome (SARS) in Guangdong province. The virus was then found to belong to the Beta-coronavirus subgroup and was later named SARS-CoV. In the case of SARS-CoV, the researchers found that raccoon dogs and palm civets were the key reservoirs for causing infection. Also, discoveries of viruses similar to SARS-CoV like horseshoe bat virus in late 2003 have proven to be a sign indicating that optimum conditions for viral introduction, replication, mutation and proliferation makes the re-emergence of such diseases possible (Cheng et al., 2007). In 2012, a novel $\beta$-coronavirus that had not previously been observed in humans was detected for the first time, which caused Middle Eastern Respiratory Syndrome and was known as MERS-CoV which affected more than 2,494 individuals across 27 countries and led to the death of 858 individuals as of November 2019. Similarly, the Middle East respiratory syndrome (MERS) coronavirus was also found to be a member of the betacoronavirus subgroup and for which camels were identified as the zoonotic source or primary host for the infection (Shereen et al., 2020). Similar to SARS-CoV-2, the original SARS-CoV, spread through human transmission chains and infected around 8000 individuals in 29 countries, and around 774 patients succumbed to death (Docea et al., 2020). On $8^{\text {th }}$ December 2019, in Wuhan, China, the first case was reported of a new

Vantage: Journal of Thematic Analysis, 2020; 1(2): 21-45 
coronavirus that produces pneumonia. Since then, the new virus initially named 2019$\mathrm{nCoV}$ and subsequently renamed SARS-CoV-2 spread rapidly via human to human transmission (Figure 2).

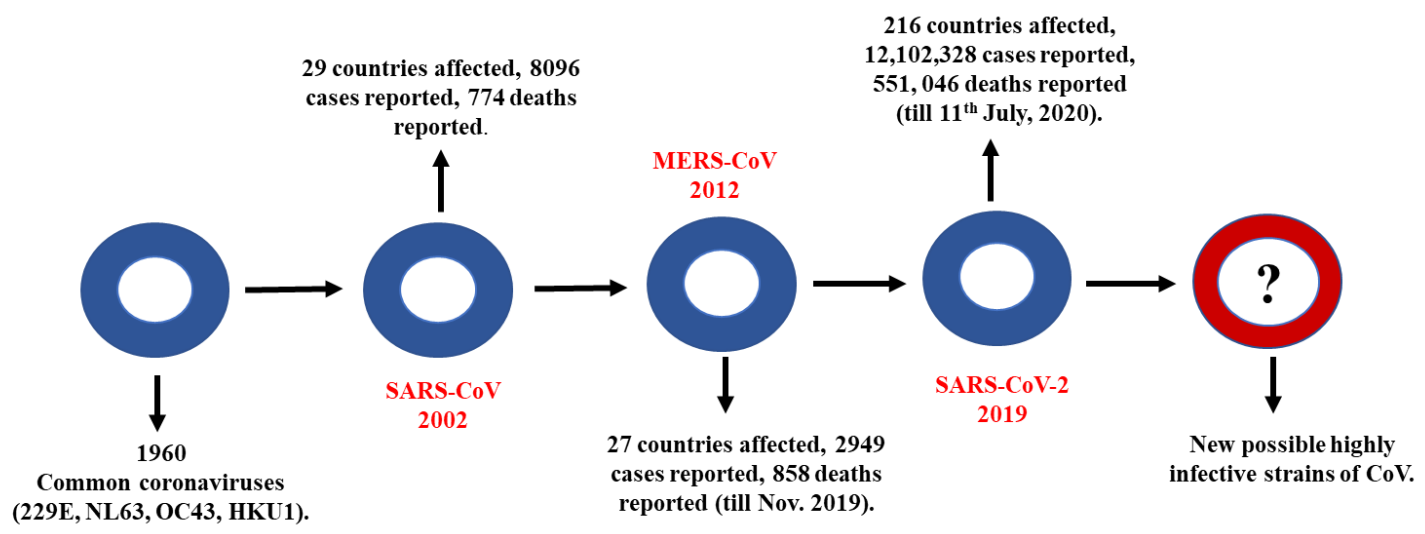

Figure 2: History of Coronaviruses pandemics (Docea et al., 2020).

Genomic studies have revealed that SARS-CoV-2 is phylogenetically similar to severe acute respiratory syndrome-like (SARS-like) bat viruses, suggesting that bats could be the possible primary reservoir of the infection. The intermediate source of origin is yet to be discovered and needs further investigation.

At the time of authoring (1 $1^{\text {th }}$ July 2020) as per the World Health Organisation (WHO), COVID- 19 so far has infected 12,102,328 people and has claimed 551,046 lives, affecting 216 countries worldwide. In recent history, several outbreaks have occurred related to these Betacoronavirus strains. Rapid economic growth and increasing demand for animal proteins in China, keeping animals in overcrowded cages, lack of biosecurity measures have allowed the spillage of this novel Coronavirus (Cheng et al., 2007). Specialists have been warning that if the conditions continue to be the same, then more such pandemics will follow shortly.

\section{SIMILARITIES AND DISSIMILARITIES BETWEEN SARS-COV AND SARS-COV-2}

SARS-CoV-2 belonging to the coronavirus family has been recognised as a novel virus responsible for the current COVID-19 crisis. Phylogenetic tree analysis of the novel coronavirus has shown that phylogenetically SARS-CoV-2 has more resemblance to Bat 
SARS-like coronaviruses than SARS-CoV. Comparatively, SARS-CoV-2 is characterized_by milder infections than other coronaviruses belonging to Betacoronavirus to which SARS-CoV-2 also belongs.

SARS- CoV-2

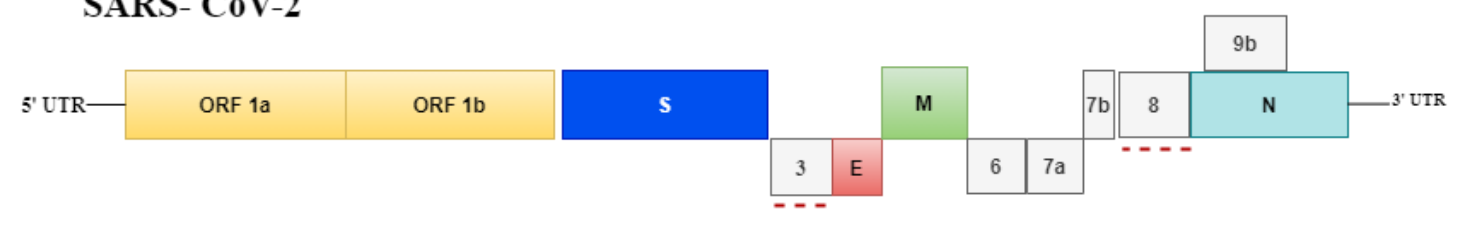

SARS-CoV

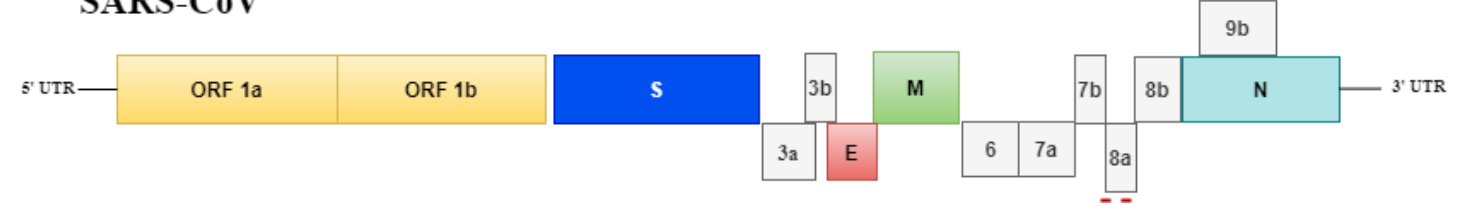

Figure 3: Genome organisation of SARS-CoV-2 and SARS-CoV. The genome comprises of 5' - untranslated regions (5'- UTR), open reading frame (ORF) $1 \mathrm{a} / \mathrm{b}$ (orange box) encoding non- structural proteins (nsps) for replication, structural proteins including the spike (dark blue box), envelop (maroon box), membrane (green box), and nucleocapsid (light blue box) proteins, accessory proteins (grey boxes) such as ORF 3,6,7a,7b,8 and 9b in the SARS-CoV-2 genome and the 3' untranslated region (3' UTR). The dotted underlined in red is the protein that shows key variation between SARSCoV-2 and SARS-CoV (Shereen et al., 2020).

The structure in terms of SARS-CoV-2 virion size $(\sim 70$ to $90 \mathrm{~nm})$ is very similar to that of SARS-CoV (Figure 3). It is found that around $70-80 \%$ similarity to SARS-CoV is shared by its genome (Kumar et al., 2020). Despite the fact, it is known to show the highest degree of similarity with a horseshoe bat coronavirus1 (Petrosillo et al., 2020). The genome is composed of six to eleven open reading frames (ORFs) with 5' and 3' flanking untranslated regions (UTRs), along with spike, membrane and envelope surface viral proteins which are embedded in host membrane-derived lipid bilayer. This is then encapsulated by an additional sheath of helical nucleocapsid comprising viral RNA. Not much difference is reported in the sequences in ORFs and nsps (non- structural proteins) of SARS-CoV-2 and SARS-CoV. The non- structural proteins are composed of two viral cysteine proteases i) main protease or chymotrypsin-like (nsp5) or ii) papain-like 
protease (nsp3). Transcription and replication of SARS-CoV-2 are controlled by RNAdependent RNA polymerase (nsp12) and helicase (nsp13) (Kumar et al., 2020).

A value of $3.8 \AA$ as root-mean-square deviation (RMSD) in the structure of the spike glycoprotein structure of SARS-CoV-2 is found to have a striking resemblance to that of the spike protein of SARS-CoV. Genomic level analysis of SARS-CoV and SARSCoV-2 shows that around 380 amino acid substitutions and 27 mutations have been found in the non-structural protein genes, and in the genes which code for viral spike protein S mediating the receptor binding and cell entry (Petrosillo et al., 2020). SARSCoV-2 is reported to transmit widely in the community in comparison to SARS which was mainly associated with nosocomial spread. Evidence based on genomic analysis suggests that similar to SARS-CoV, SARS-CoV-2 also uses the AngiotensinConverting Enzyme 2 (ACE2) receptor for Spike (S) protein priming via internalization and Transmembrane protease serine 2 (TMPRSS2). The pathogenicity of the SARS$\mathrm{CoV}$ has increased significantly due to the mutations in the receptor binding domain (RBD) of S protein thereby increasing its affinity with the receptor as a whole supporting the view that SARS-CoV-2 might also have evolved the same way. Amino acid substitutions in the RBD of SARS-CoV-2 directly interact with receptor ACE2 of the human body in comparison to SARS CoV, although six mutations have taken place in other regions of the RBD. It is, therefore, necessary to go for further investigation whether the higher receptor affinity for ACE2 of SARS-CoV-2 would lead to even more severe lung involvement than SARS or not. It is still unknown if SARS-CoV N protein of SARS-CoV acts the same way as that of SARS-CoV-2, but neutralization to the immune response of the host via nucleocapsid $(\mathrm{N})$ protein is the same in both of the genera. High Reproductive number $\left(\mathrm{R}_{0}\right)$ is often regarded as a symbol of highly diffusible infections, with a long incubation period, but symptoms being mild-tomoderate. This in turn results in a low mortality rate. As per the data by the World Health Organization (WHO), SARS-CoV-2 has a higher pandemic potential since its $\mathrm{R}_{0}$ is estimated to range between 2 and 2.5 while that of SARS was around 1.7 -1.9 (Table 1). 
Table 1: Comparison between SARS-CoV and SARS-CoV-2 (Ceccarelli et al., 2020)

\begin{tabular}{|c|c|c|}
\hline Characteristics & SARS- COV & SARS- COV 2 \\
\hline Target receptor & ACE-2 & ACE-2 \\
\hline Nucleocapsid protein & Interferon-g (IFN-g) inhibitor & Unknown \\
\hline Phylogenetic origin & Clade I, cluster IIb & Clade I, cluster IIa \\
\hline Animal reservoir & Bats & Bats \\
\hline Intermediate host & Palm civets & Unknown \\
\hline $\begin{array}{l}\text { Reproductive } \\
\text { number }\left(\mathrm{R}_{\mathrm{o}}\right)\end{array}$ & 0.4 & $1.4-2.5$ \\
\hline Chest X-ray & Ground glass opacities & $\begin{array}{l}\text { multilobed and bilateral ground glass } \\
\text { opacities }\end{array}$ \\
\hline Chest CT-scan & $\begin{array}{l}\text { Lobar consolidation } \\
\text { Nodular opacities }\end{array}$ & No nodular opacities \\
\hline Prevention & $\begin{array}{l}\text { Maintaining good hygiene, } \\
\text { following cough etiquettes }\end{array}$ & $\begin{array}{l}\text { Maintaining good hygiene, following } \\
\text { cough etiquettes }\end{array}$ \\
\hline Transmission & $\begin{array}{l}\text { Via droplets or direct contact with } \\
\text { an infected person }\end{array}$ & Via droplets \\
\hline Incubation period & $4-10$ days & 3- 7 days \\
\hline Death period & 20- 25 days & 17- 24 days \\
\hline Symptoms & $\begin{array}{l}\text { dry cough, fever, myalgia, } \\
\text { dyspnea, confusion, headache, } \\
\text { sore throat, sputum production, } \\
\text { rhinorrhea, watery diarrhoea, poor } \\
\text { appetite }\end{array}$ & $\begin{array}{l}\text { Fever, cough, dyspnea, muscle ache } \\
\text { confusion, headache, sore throat, } \\
\text { rhinorrhea, chest pain, diarrhoea, } \\
\text { nausea, vomiting, anosmia }\end{array}$ \\
\hline $\begin{array}{l}\text { Case fatality rate } \\
\text { (overall) }\end{array}$ & $9.6 \%$ & $2.3 \%$ \\
\hline
\end{tabular}

As per a recent study carried out by the Chinese Centre for Disease Control and Prevention (CCDC) on 44,672 individuals diagnosed with COVID-19 in China, the fatality rate of the novel coronavirus infection was estimated to be $2.3 \%$, lower than that of SARS (9.5\%) (Petrosillo et al., 2020). Detection of SARS-CoV-2 RNA in the stools of infected patients has been reported similar to SARS-CoV. In relevance to its demographic characteristics, clinical and radiological findings SARS-CoV is found similar to SARS-CoV-2. Clinical complications in SARS-CoV-2 are as frequent as in SARS, but often less severe comparatively and thus it spreads more rapidly in the community than SARS. 


\section{LIFE CYCLE OF CORONAVIRUS}

Coronavirus goes through a replication life cycle within a host cell, thereby creating more copies of it that can eventually infect more cells. Here, the replication cycle of SARS-CoV2 is explained along with possible inhibitors and their respective targets. This compilation is based on the current literature; however, the accuracy of the life cycle and how the disease develops are the aspects which are yet to be resolved fully (Figure 4; Figure 5).

\subsection{Viral Entry}

For virion replication to begin, the spike proteins first bind to specific host cell surface receptors that are embedded in the host cell membrane - a process called host cell recognition. The sites of receptor binding domains (RBD) within the S1 region of a coronavirus S glycoprotein have the RBD at the C-terminus. Inhibitors like Griffithsin (Inhibitor II) bind to the spike glycoprotein, thus preventing viral entry (Hoffmann et al., 2020). RBD also governs the tissue tropism of the virus. Many coronaviruses utilize peptidases as their cellular receptor though entry occurs even in the absence of the enzymatic domain of these proteins. SARS-CoV utilizes ACE2 as its receptor. It has been confirmed that ACE2 facilitates the viral entry in the various organs such as the heart, lungs, intestine, and kidneys which contain the receptor with a high occurrence in ciliated and secretory cells/goblet cells of the nasal epithelium (Sungnak et al., 2020).

SARS-CoV-2 can gain entry in the cell in two ways, either via endosomes or via plasma membrane fusion. When virions are taken up into endosomes, cathepsin $\mathrm{L}$ activates the spike protein accomplished by acid-dependent proteolytic cleavage of S protein. The $\mathrm{pH}$-dependent cysteine protease can be blocked by lysosomotropic agents, like bafilomycin A1 or ammonium chloride (Inhibitor Classes III, IV). Alternatively, the spike protein can be activated by the cellular serine protease TMPRSS2 in close proximity to the ACE2 receptor, which initiates fusion of the viral membrane with the plasma membrane (Inhibitor I: Camostat) (Hoffmann et al., 2020). The plasma membrane fusion entry is less likely to trigger host cell antiviral immunity and therefore more efficient for viral replication (Shirato et al., 2018).

\subsection{Translation of Viral Replication Machinery}

The virion genome has a replicase gene that undergoes translation thus encoding rep1a and rep1b. These two large ORFs express pp1a and pp1ab proteins arranged coterminally by nsp11 (pp1a) extension joining with nsp12 (pp1b) (Perlman and Netland, 
2009). Polyproteins pp1a and pp1ab contain the nsps 1-11 and 1-16, respectively. In pp1ab, nsp11 from pp1a becomes nsp12 following extension of pp1a into pp1b. Cleavage of replicase polyproteins is encoded either two or three proteases. They are the papain-like proteases (PLpro), encoded within nsp3, and nsp5 encode the chymotrypsin-like protease (3CLpro) or main protease, (Mpro), a serine type protease. Most coronaviruses encode two PLpros within nsp3, except the $\gamma$-coronaviruses, SARSCoV and MERS-CoV, which only express one PLpro (Saikatendu et al., 2005).

CoV nsp 12 and AV nsp9 are important as their domain form replicase-transcriptase complex (RTC) in double-membrane vesicles (DMVs), an assembly by RNA-dependent RNA polymerase (RdRp) and helicase-containing subunits (Perlman and Netland, 2009). This complex transcribes viral genome to negative-sense progeny genome and sub-genomic RNA, followed by transcription to positive-sense mRNAs mediated by RdRp (Astuti \& Ysrafil, 2020). The current model proposes that the RdRp pauses at any one of the body TRS sequences (TRS-B); following this pause the RdRp either continues elongation to the next TRS or it switches to amplifying the leader sequence at the $5^{\prime}$ end of the genome guided by the complementarity of the TRS-B to the leader TRS (TRS-L) (Fehr and Perlman, 2015). Many pieces of evidence currently support this model including the presence of anti-leader sequence at the $3^{\prime}$ end of the negative strand sub-genomic RNAs (Serrano et al., 2007). However, many questions remain to be answered to fully define the model. RdRp can be inhibited by virostatica like Favipiravir or Penciclovir (Inhibitor V); the replication of viral RNA in general by kinase signaling pathway inhibitors like Saracatinib (Inhibitor VI) (Shin et al., 2016).

Next, structural and accessory proteins are produced by translation of the sub-genomic RNA. The synthesized M, S and, E proteins enter the endoplasmic reticulum and mature in the endoplasmic reticulum-Golgi intermediate compartment (ERGIC). In the meantime, the $\mathrm{N}$ protein is joined by the genome to form nucleocapsid and enters ERGIC. There, nucleocapsids join with other structural proteins and are finally released by exocytosis in the form of vesicles. How the nucleocapsid complexed with virion RNA traffics to the ERGIC compartment, to act together with $\mathrm{M}$ protein and become incorporated into the viral envelope is still not clear. Another point that is yet to be found is how the $\mathrm{N}$ protein selectively packages only positive sense full length genomes.

Vantage: Journal of Thematic Analysis, 2020; 1(2): 21-45 


\subsection{Assembly and Release of Virion}

Virions reach the cell surface via vesicles and are released by exocytosis. However, it is not clear if the virions use the traditional pathway for transport of large cargo from the Golgi or they divert a separate, unique pathway for its exit. In several coronaviruses, $S$ protein that does not get assembled into virions transits to the cell surface where it mediates cell to cell fusion between infected cells and adjacent, uninfected cells (Qinfen et al., 2004). It is followed by the formation of giant, multinucleated cells, which allows the virus to spread within an infected organism without being neutralized/ detected by specific antibodies. Oseltamivir is known to inhibit cleavage of sialic acids by neuroamidase from the cell receptors thus preventing the release of newly formed (influenza) virions from the cell surface (Inhibitor X) (McKimm-Breschkin, 2012).

A study says, both the entry and release of the virus occur through membrane fusion. The nucleocapsid formed in RER, matures in the smooth vesicle of the Golgi apparatus, buds off and fuses with the cell membrane to release mature viral particles. It also reports the appearance of viral particles in the nucleus of a cell (Lu et al., 2010).

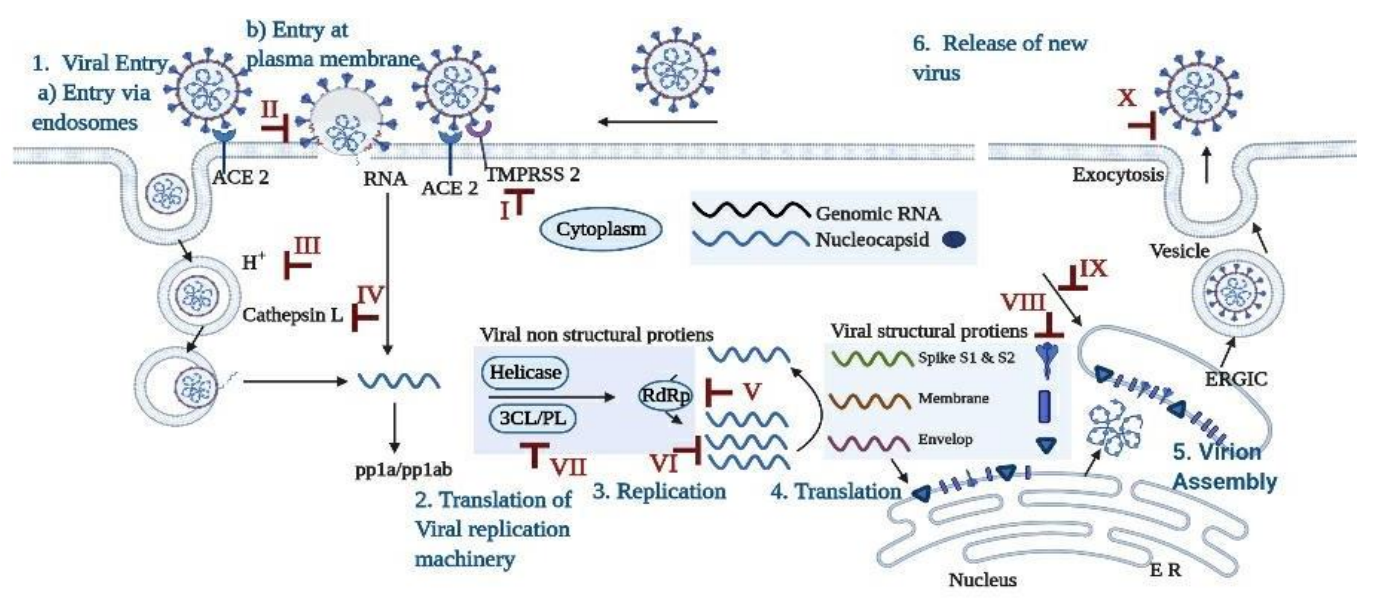

Figure 4: A viral infected cell showing events of the SARS COV 2 life cycle with possible inhibitors (Abu-Farha et al., 2020; Alanagreh et al., 2020; Guy 2020). (Abbreviations: ACE-2 Angiotensin-Converting Enzyme 2; ER Endoplasmic Reticulum; TMPRSS-2 Transmembrane protease serine 2 and RdRp RNA dependent RNA Polymerase)

(Inhibitors: I - Camostat; II - Griffithsin; III-Chloroquine; IV-MDL28170; VFavipiravir, Penciclovir; VI - Dasatinib, Saracatinib; VII -Lopinavir; VII -Furin; IX Reservatrol and $\mathrm{X}$-Osaltamivir) 


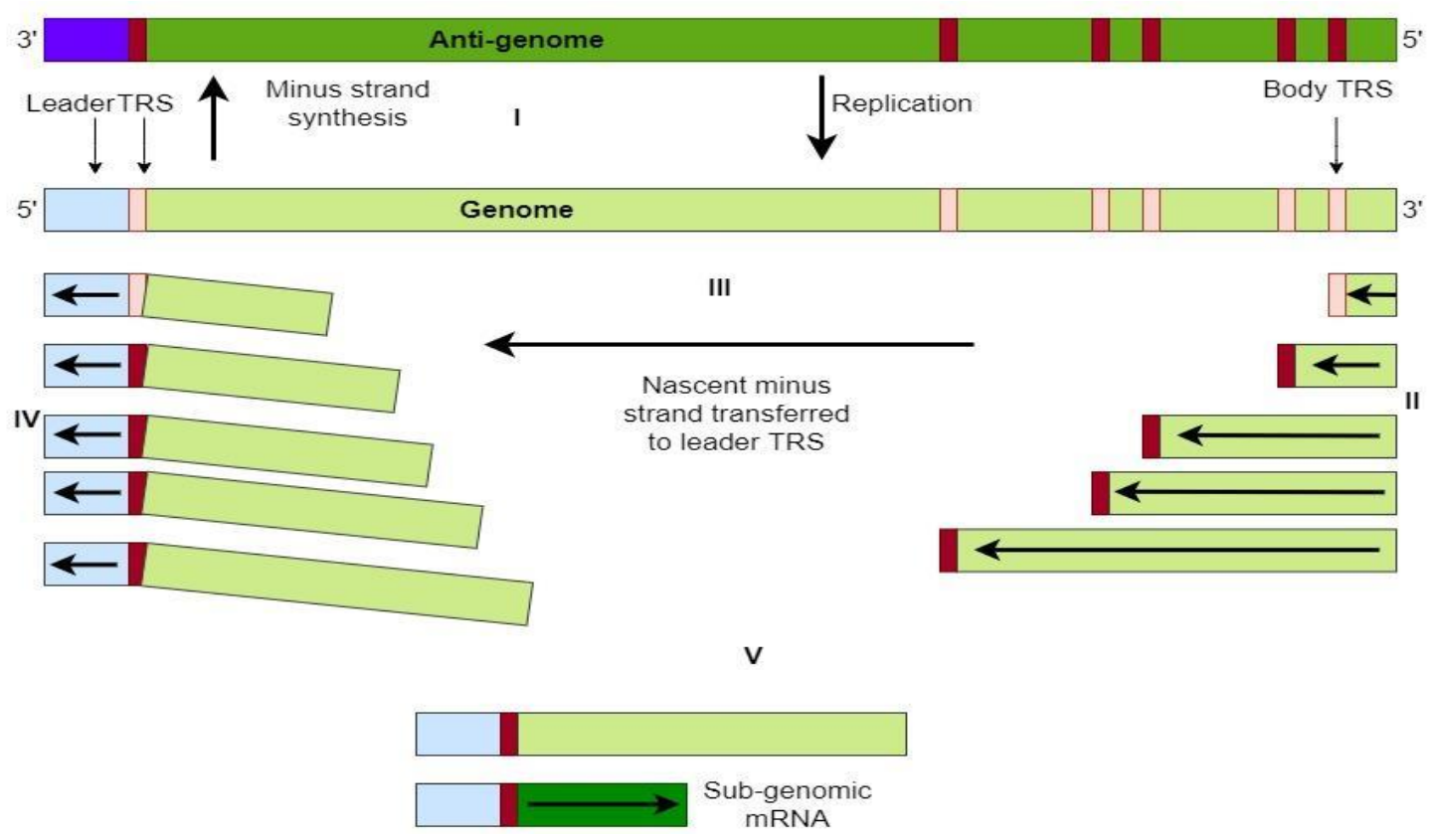

Figure 5: Genome as a template to generate full-length negative sense RNAs, which subsequently serve as templates in generating additional full-length genomes

(I). Sub-genomic RNAs are initiated at the 3' end of the genome and proceed until they encounter one of the transcriptional regulatory sequences (TRS; red) that reside upstream of most open-reading frames (II). Through base-pairing interactions, the nascent transcript is transferred to the complementary leader TRS (pink) (III) and transcription continues through the $5^{\prime}$ end of the genome (IV). These sub-genomic RNAs then serve as templates for viral mRNA production (V) (Perlman \& Netland, 2009).

\section{PATHOGENESIS AND CLINICAL MANIFESTATIONS}

SARS-CoV-2 is an RNA virus responsible for zoonotic infection. The incubation period of this virus is within 14 days following exposure while the median incubation period is 4 days. The major mode of transmission is human to human via air-borne large droplets with a risk limited to $\sim 6 \mathrm{ft}$ from the patient. The other mode of transmission is contact transmission via fomites, as the large droplets settle on the surface and contaminate it. $80 \%$ of the SARS-CoV-2 infections are mild, which usually recover within 14 days. The most common symptoms as observed are fever, followed by fatigue and dry cough. The gastrointestinal infections differentiate SARS-CoV-2 from SARS and MERS (Sharma et al., 2020). The infection initiates with fever, dry cough, fatigue, myalgia and 
then progressing to dyspnoea and Acute Respiratory Distress Syndrome (ARDS) over 6 to 8 days post-exposure.

The overall mortality rate ranges from 1.5 to $3.6 \%$. SARS-CoV-2 like the SARS virus binds to the human Angiotensin-Converting Enzyme-2 receptor (hACE-2) located on the host's type II alveolar and intestinal cells. The virus infects the respiratory tract using the hACE-2 receptor leading to a systemic illness with the virus being present in the blood, urine and faeces (Brüssow, 2012). In the initial few days, an infected person moves through various stages of replication subsequently followed by a stage of adaptive immunity over the next few days.

In the replicative stage, the virus replicates, leading to influenza-like illness characterized by mild symptoms. In the stage of adaptive immunity, the immune system takes over leading to the decline in the viral levels, but the inflammatory cytokine storm leads to tissue destruction and clinical deterioration. The spectrum of disease ranges from asymptomatic or mild disease in $81 \%$ with a usual recovery period of about 2 weeks, to severe diseases like dyspnoea, hypoxia or more than $50 \%$ lung involvement on imaging within $24-48 \mathrm{hrs}$ in $14 \%$ with a recovery phase of about $3-6$ weeks. The disease may be very critical (ARDS, sepsis, septic shock) in 5\% as observed in data of COVID-19 cases from the Chinese Centre for Disease Control and Prevention (Sharma et al., 2020).

It mainly affects middle-aged and elderly aged people, the highest fatality rate is in persons above 80 years of age; this might be due to increased expression of the hACE2 receptor in them and also due to higher rates of smoking which further leads to increased expression of the hACE-2 receptor (Sharma et al., 2020). But these are just speculations and further studies involving other backgrounds are required.

Physical examination is nonspecific and unremarkable with less than $2 \%$ having pharyngitis or tonsillar enlargement. Upon entry into the host target cells, the viral antigens get presented via antigen presenting cells (APCs) to virus-specific cytotoxic T lymphocytes (CTL). However, CTL epitopes of SARS-CoV-2 have been predicted by several studies, which may be used for understanding the pathogenesis and development of peptide-based vaccines. Studies have shown activation and reduction in CD4+ and 
CD8+ T cell counts in SARS-CoV-2 infected patients (Kumar et al., 2020; Saxena et al., 2020).

\section{COMBATING MEASURES AGAINST SARS-COV-2}

On $11^{\text {th }}$ March 2020, SARS-CoV-2 was declared as a global pandemic by the World Health Organisation (WHO) which is severely affecting the whole world in not only health perspectives but also taking away the income sources of the vast majority of the population. Countries are facing an economic crisis and inter-country tensions are also arising. To be able to combat the situation of this pandemic and its consequences, scientists all over the world are searching for possible drugs, vaccines, pharmacological and therapeutic approaches. Though the very first approach of containing the infection was a worldwide lockdown and quarantining those who were carrying the infection, this is not the ultimate solution. It might have slowed down the rate of transmission but lakhs of people are still getting infected, increasing the load on the medical capacity of a country. This review article aims to track the treatment strategies used to cure the previous SARS infection and the possible approaches to make a breakthrough for SARS-CoV-2. Any specific treatment for the eradication of SARS-CoV-2 is yet to be announced though there are claims of the possible vaccines that can help mitigate this pandemic.

\subsection{Containment Measures}

The first approach worldwide at the advent of the coronavirus infection was containment. It was the technique that China used extensively in those areas which showed a large number of infected individuals. India has adopted this technique from early March onwards. The nationwide lockdown was followed with innovative quarantine facilities. Indian Railway Department took an initiative to convert the railway coaches into isolation beds for COVID infected patients. Awareness is being spread at various levels to follow preventive measures. To track the infection to control the spread, digital tools like the Arogya Setu application was developed. It's a mobile-based application that uses Bluetooth and GPS capabilities to track COVID-infected persons. 
Statistical studies have shown that the reproduction number of COVID 19 has been on a declining trend, indicating lower spreading rates through containment and strict isolation measures. The continued effort from across the world will be needed to fully understand the coronavirus family in order to prevent future outbreaks.

\subsection{Therapeutic Measures}

One approach of finding a specific drug or vaccination (like chloroquine and hydroxychloroquine) for treating SARS is through tracing the drugs used in previous coronavirus treatment and administering it for SARS CoV 2 until a specific drug is developed for the treatment. Reports have shown that ribavirin has a high rate toxicity association and a lack of in-vitro antiviral effect on SARS-coronavirus (SAR-CoV) (Astuti \& Ysrafil, 2020). There is controversy in the timing and dosage administration of steroids in the treatment of SARS. Pulse methylprednisolone (250 to $500 \mathrm{mg} /$ day) for 3 to 6 days has been reported to have some effectiveness in a subset of patients with critically ill SARS patients (Tai, 2007). Positive results were shown by drug alphainterferon and combination of the interferon A with ribavirin or steroids. Results were evident as an increase in lung repair and oxygen levels observed in some cases. The drug delivery methods were either by - aerosol inhalation in case of alpha interferon given two times per night or continuous dosage on combined therapy for 28 days in MERS patients, where positive results were only observed till the initial 14 days (Loutfy et al., 2003). Interferon (IFN) is not suggested as customary therapy in SARS. However, there is enough data on in vitro activity of IFN preparations but a few clinical studies for these products to support controlled trials.

Drugs focusing on ways to stop or slow the spread of virus and replication of virus at the cellular level in the host can be a cure to patients infected with the virus. With the advancement in Molecular biology, investment in siRNA or micro RNA based therapeutic approaches to block ACE2 receptors can prove valuable against coronavirus as micro RNA has already been a proven solution in the pathogenesis of ARDS-induced coronaviruses. Dr. Brijesh Rathi, Assistant Professor in the Chemistry Department of 
Hansraj College has conducted In-silico experiments. He claims a drug solution named Calxinin against SARS-CoV-2 (Duexpress, 2020).

It should be taken care that experimental treatments have been tried in an uncontrolled manner, and they should not be recommended as standard therapy. WHO and several partners launched "Solidarity" as an international clinical trial to facilitate and fund an effective treatment for COVID-19. Until, there is any sufficient evidence, WHO cautions against physicians and medical associations recommending or administering these unproven treatments to COVID-19 patients or people self-medicating with them. WHO is concerned by such reports of individuals who are self-medicating themselves with chloroquine. Concerning this, on 23 May 2020, the Executive Group of the Solidarity Trial decided to implement a temporary suspension of the hydroxychloroquine (WHO, 2020). On 3rd June 2020, WHO's Director-General announced no reasons to modify the trial protocol. The Executive Group received this proposal and allowed the furtherance of all arms of the Solidarity Trial, including hydroxychloroquine. Recently, The World Health Organization called for a rapid increase in production of the steroid dexamethasone, after preliminary British clinical trials. The trial on 2000 patients showed that it reduced deaths by 35 percent. WHO approved the likelihood of steroid dexamethasone as a life-saving drug for critically ill patients of COVID-19.

\subsection{Vaccines}

Vaccines have only been approved for Infectious Bronchitis Virus (IBV), Transmissible Gastroenteritis Virus (TGEV) and Canine CoV (Astuti \& Ysrafil, 2020) but these vaccines are not always administered because of ineffectiveness and they can be involved in the selection of novel pathogenic $\mathrm{CoVs}$ via recombination of circulating strains.

Table2: Advantages and Disadvantages of different Vaccine strategies (Song et al., 2019)

\begin{tabular}{|l|l|l|}
\hline \multicolumn{1}{|c|}{ Vaccine strategy } & \multicolumn{1}{|c|}{ Advantages } & \multicolumn{1}{c|}{ Disadvantages } \\
\hline $\begin{array}{l}\text { Inactivated virus } \\
\text { vaccines }\end{array}$ & $\begin{array}{l}\text { Easy to prepare, safe, high-titer } \\
\text { neutralizing antibodies }\end{array}$ & $\begin{array}{l}\text { Potential inappropriate for highly } \\
\text { immune- suppressed individuals }\end{array}$ \\
\hline
\end{tabular}

Vantage: Journal of Thematic Analysis, 2020; 1(2): 21-45 


\begin{tabular}{|l|l|l|}
\hline $\begin{array}{l}\text { Attenuated virus } \\
\text { vaccines }\end{array}$ & $\begin{array}{l}\text { Rapid development, induces high } \\
\text { immune responses }\end{array}$ & $\begin{array}{l}\text { Phenotypic or genotypic reversion } \\
\text { possible, can still cause some disease }\end{array}$ \\
\hline Subunit vaccines & $\begin{array}{l}\text { High safety, consistent production, } \\
\text { can induce cellular and humoral } \\
\text { immune responses, high-titer } \\
\text { neutralizing antibodies }\end{array}$ & $\begin{array}{l}\text { High cost, lower immunogenicity, } \\
\text { require repeated doses and adjuvants }\end{array}$ \\
\hline $\begin{array}{l}\text { Viral vector } \\
\text { vaccines }\end{array}$ & $\begin{array}{l}\text { Safety, induces high cellular and } \\
\text { humoral immune responses }\end{array}$ & Possibly present pre-existing immunity \\
\hline DNA vaccines & $\begin{array}{l}\text { Easier to design, high safety, high- } \\
\text { titer neutralizing antibodies }\end{array}$ & $\begin{array}{l}\text { Lower immune responses in humans, } \\
\text { repeated doses may cause toxicity }\end{array}$ \\
\hline mRNA vaccines & $\begin{array}{l}\text { Easier to design, a high degree of } \\
\text { adaptability, induce strong immune } \\
\text { responses }\end{array}$ & $\begin{array}{l}\text { Highly unstable under physiological } \\
\text { conditions }\end{array}$ \\
\hline
\end{tabular}

Quite a lot of potential vaccines have been developed for SARS-CoV but are yet to be permitted for use. These vaccines include: (i) recombinant attenuated viruses, (ii) live virus vectors, or (iii) individual viral proteins expressed from DNA plasmids. Recombinant protein from the Urbani (AY278741) strain of SARS-CoV was administered to mice and hamsters which resulted in the production of neutralizing antibodies and protection against SARS-CoV (Shereen et al., 2020). The DNA fragment inactivated the whole virus or live-vectored strain of SARS-CoV (AY278741) significantly reduced the viral infection in various animal models (Table 2).

Few vaccines against SARS-CoV-2 are the mRNA-based vaccine prepared by the US National Institute of Allergy and Infectious Diseases against SARS-CoV-2 which is under phase 1 trial. Human testing is expected to start soon for INO-4800- DNA based vaccine. Chinese Centre for Disease Control and Prevention is working on the development of an inactivated virus vaccine. GeoVax-BravoVax is also working on the development of a modified Vaccinia Ankara (MVA) based vaccine. Clover Biopharmaceuticals is developing a recombinant 2019-nCoV S protein subunit-trimer based vaccine.

\section{VACCINE TARGETING ACE2 RECEPTORS}

Following are the possible approaches based on structural receptor proteins functional in the life cycle of COVID 19 
1. Blocking ACE2 receptor- The atomic-level observations showed that SARS-CoV-2 interacts with ACE2 and hence can be a possible target of antibodies.

2. Spike protein-based vaccine- Sub-unit of Spike1 protein-based vaccine can prove efficient on a large scale targeting ACE2 receptors containing cells that facilitate viral replication. Studies on combined DNA demonstration on mice showed that neutralizing antibodies and $\mathrm{T}$ cell immune response gets generated when spike protein is used (Du et al., 2009)

3. Inhibiting transmembrane protease serine2 (TMPRSS2) activities - Camostat mesylate is a proven inhibitor of TMPRSS2 activity used in the treatment of an unrelated disease in Japan. Due to the interaction of TMPRSS2 with ACE2 in the entry of SARS-CoV-2, the inhibitor might prove to be a potential solution (Zhang et al., 2020).

4. Providing excessive ACE2 in soluble form - This serves in two ways:

a. Slowing the viral entry - based on the competitive binding phenomenon, excessive ACE2 may bind and neutralize SARS-CoV-2 and;

b. Protecting lung injury - by rescuing cellular ACE2 activity which plays a role in negative regulation of the Renin-Angiotensin System (RAS) thus preventing lung damage. (Zhang et al., 2020) (Figure 6).

Cross-resistance of other vaccines for other diseases such as rubella or measles has also worked for SARS-CoV-2. This statement of cross-resistance is based on the observations that children in China were found less vulnerable to infection as compared to the elder population, while children are being largely vaccinated for measles in China (Zhang et al., 2020). 


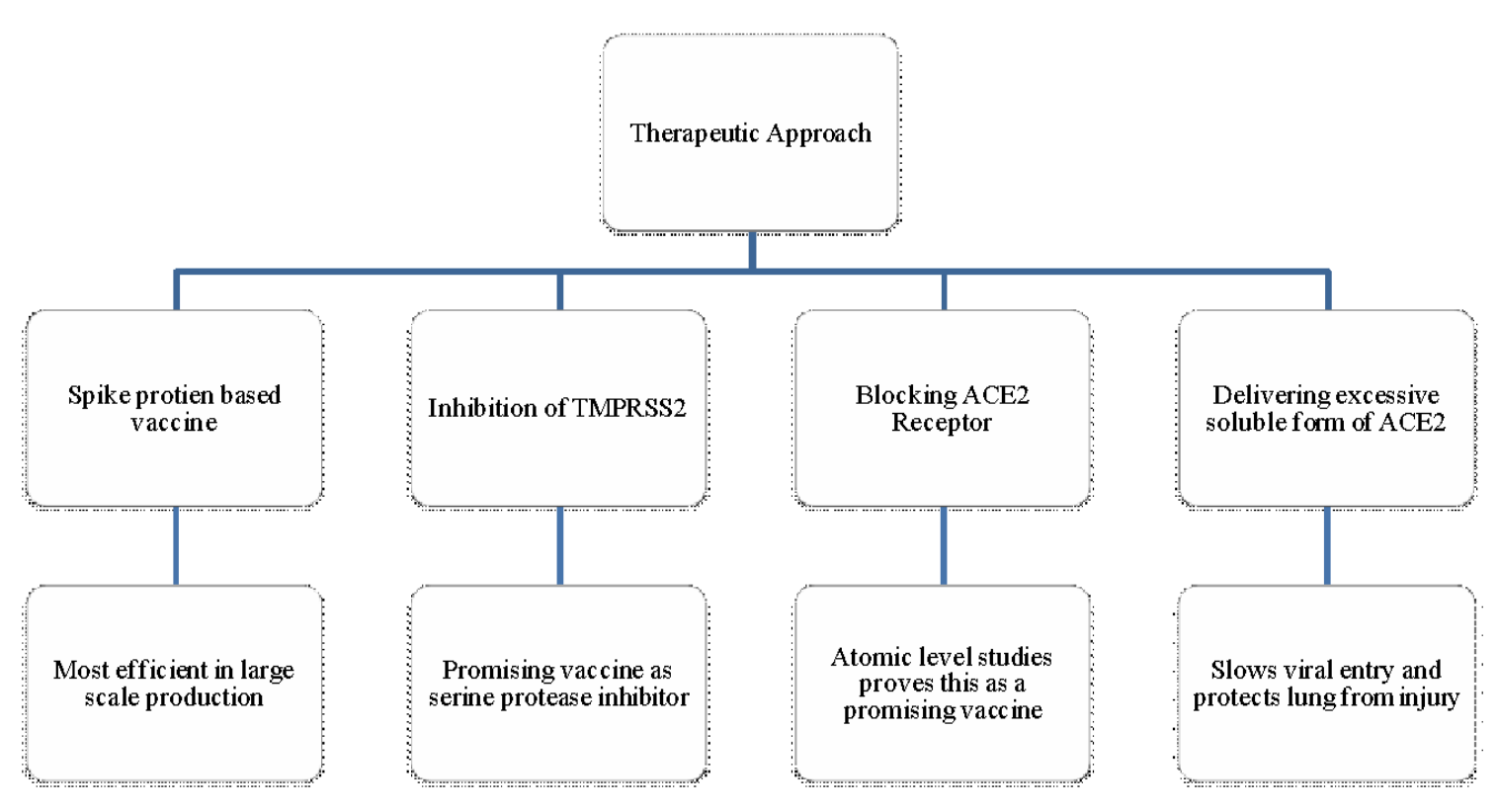

Figure 6: Potential therapeutic approaches to address ACE-2 mediated COVID-19.

\section{VACCINE DEVELOPMENT FOR CORONA VIRUSES FACE MANY CHALLENGES -}

1. Patients having mucosal infection may get infected again hence the vaccines must induce a strong immune response than the virus and reduce the intensity of infection in case secondary infection occurs.

2. The virus recombines at a very fast rate which renders the current vaccine purposeless. Also, the vaccine might cause the evolution of the virus in the wild adding to its diversity.

3. Feline Infectious Peritonitis Virus (FIPV) shows that vaccination with S protein causes more severe disease. Despite this, vaccine development strategies to decrease the occurrence of recombination are made, for example, deletions in the nsp1 or E proteins, rearranging the $3^{\prime}$ end of the genome, modifying the TRS sequences, or using mutant viruses with high mutation rates that attenuate the virus significantly (Fehr, 2015). If experimental treatments are proven to be successful then, they should be further studied in the form of clinical trials to get a measure of their safety, efficiency, risks and future/ other benefits. 


\section{DISCUSSION}

Experts have predicted that the coronaviruses might emerge again. Therefore, to predict the potential place and time of its recurrence, we need to understand the nature of the zoonotic shift. Studies indicated bats to be a reservoir for these viruses, yet their ability to avoid clinically evident disease inside bats and still persistently infecting them can be significant to approach further possibilities of infection.

Further, SARS-CoV appeared to use a completely new receptor on shifting from bats to palm civets and humans. During transmission to a new species, they need to evade the innate immune response of the new hosts. A better understanding of its interaction with the $\mathrm{T}$ and $\mathrm{B}$ cell responses, both in the original host (bats), in which disease appears to be mild, and in humans and experimentally infected animals might further demarcate how the virus evades the immune response.

There are several nonstructural and accessory proteins encoded by the viruses whose mechanism of action in the life cycle is yet to be identified. On further detailed studies of viral replication and pathogenesis, we can discover many therapeutic targets to combat the infection that might be related to these non-structural protein targets.

The viruses use a unique RNA replication process, hence gaining a complete picture of the intricacies of the RTC (Replicase-Transcriptase Complex) will provide a framework for understanding them. Although their replication strategies utilize host proteins, it has been observed that immune, metabolic stress, cell cycling, and other pathways are activated by infection. The biological function of these pathways in virus replication still needs to be assessed.

Techniques like genomics and proteomics, as well as new reagents and collaborative cross mice, can help in determining the extent to which virus-host interactions are coronavirusspecific and organ-specific. Although presumed functions have been assigned to many of the proteins encoded by the large ORF1 replicase gene, the precise additional investigation progress in these fields will take advantage of new methodologies that allow detailed observations of both fixed and living cells at high resolution.

Finally, no effective treatments exist for any coronavirus infections, including SARS140 vaccines, and live attenuated vaccines are prone to recombination with circulating 
coronaviruses. One future goal would be to translate new information about the structure and function of coronavirus proteins into specific antiviral therapies. Also, the development of live, attenuated, safe vaccines that do not recombine in the wild is another goal, making it more feasible.

\section{CONCLUSION}

Although we have traced the possible path of re-emergence of the SARS-CoV-2, its life cycle and the inhibitors at various stages inside the host cell, there is still a lot of information that is yet to be discovered. The first approach to fight the crisis was isolation and containment, yet due to many discrepancies, it did not prove to be that successful. Now the whole world is dealing with the crisis, quarantining and isolation are no longer proving to be a solution.

Another approach of developing herd immunity is through letting it infect and spread which will result in the development of natural immunity amongst humans. Though it cannot be the course of action as it will create a catastrophe and the possibility of getting re-infected will put all the loss for nothing. Therefore, human coronaviruses-targeting vaccines and antiviral drugs should be designed that could be used against the current as well as future epidemics. Many companies are working on the development of effective SARS-CoV-2 vaccines, such as Moderna Therapeutics, Inovio Pharmaceuticals, GeoVax-BravoVax, and Clover Biopharmaceuticals. There is a call for fast human and animal-based trials as these vaccines still need at least 3-10 months for commercialization. Besides the development of more efficient drugs, a strategy to rapidly diagnose SARS-CoV-2 in a suspected patient is also required as PCR based testing is expensive and time-consuming. The choice to recommend a patient for an unproven or experimental treatment is between the doctor and the patient but must abide by national law. Wherever there is a possibility and feasibility for the treatment to be given as part of a clinical trial, this should be done with complete consent from the patient. If it is not possible to give the treatment as part of a clinical trial, appropriate records of the use of the medicine must be kept, in compliance with national law, and outcomes for patients should be monitored and recorded. Any effective vaccine is yet to be developed hence to control human coronaviruses a vigilant public health surveillance system along with quick diagnosis and quarantining when necessary is a suitable 
approach. For international outbreaks, the cooperation of governmental entities, public health authorities, and health care providers is critical. To prevent further pandemics and the emergence of such viruses, there must be a complete ban on utilizing wild animals and birds as a source of food. Biosecurity should be well taken care of. By investing time and the future to research and development and harmonizing our lifestyle with nature we can avoid the possibility of such pandemics.

\section{CONFLICT OF INTEREST}

None

\section{ACKNOWLEDGEMENT}

We would like to express our heartfelt gratitude to Dr Haritma Chopra, Principal, Maitreyi College, University of Delhi, for all the support and encouragement. We gratefully recognize the overwhelming support and constant cooperation from Department of Botany, Maitreyi College. We would like to thank the Centre for Research, Maitreyi College, University of Delhi for giving us the opportunity to carry out the research project.

\section{REFERENCES}

Abu-Farha, M., Thanaraj, T.A., Qaddoumi, M. G., Hashem, A., Abubaker, J. \& AlMulla, F. (2020). The Role of Lipid Metabolism in COVID-19 Virus Infection and as a Drug Target. Int. J. Mol. Sci. 21(10), 3544. doi: 10.3390/ijms21103544.

Alanagreh, L., Alzoughool, F. \& Atoum, M. (2020). The Human Coronavirus Disease COVID-19: Its Origin, Characteristics, and Insights into Potential Drugs and Its Mechanisms. Pathogens. 9(5), 331.doi:10.3390/pathogens9050331.

Astuti, I. \& Ysrafil (2020). Severe Acute Respiratory Syndrome Coronavirus 2 (SARSCoV-2): An overview of viral structure and host response. Diabetes \& Metabolic Syndrome: Clinical Research \& Reviews, 14(4), 407-412. doi: https://doi.org/10.1016/j.dsx.2020.04.020.

Brüssow, H. (2012). On Viruses, Bats and Men: A Natural History of Food-Borne Viral Infections. In G. Witzany, (ed.) Viruses: Essential Agents of Life. 25, (pp 245- 
67). New York London: Springer Dordrecht Heidelberg. doi: 10.1007/978-94007-4899-6. ISBN 978-94-007-4898-9.

Ceccarelli, M., Berretta, M., Venanzi Rullo E., Nunnari, G. \& Cacopardo, B. (2020). Differences and similarities between Severe Acute Respiratory Syndrome (SARS)-CoronaVirus (CoV) and SARS-CoV-2. Would a rose by another name smell as sweet? Eur. Rev. Med. Pharmacol. Sci. 24(5), 2781-2783. doi:10.26355/eurrev_202003_20551.

Cheng, V. C. C., Lau, S. K. P., Woo, P. C. Y. \& Yuen, K. Y. (2007). Severe Acute Respiratory Syndrome Coronavirus as an Agent of Emerging and Reemerging Infection. Clinical Microbiology Reviews. 20 (4), 660-694. doi: 10.1128/CMR.00023-07.

Docea, A. O., Tsatsakis, A., Albulescu, D., Cristea, O., Zlatian, O., Vinceti, M., Moschos, S. A., Tsoukalas, D., Goumenou, M., Drakoulis, N., et al., (2020). A new threat from an old enemy: Re-emergence of coronavirus (Review). Int. J. Mol. Med. 45, 1631-1643.

Du, L., He, Y., Zhou, Y., Liu, S., Zheng, B. \& Jiang, S. (2009). The spike protein of SARS-CoV - a target for vaccine and therapeutic development. Nature Rev. Microbiol. 7, 226-236.

Duexpress, (2020). Anti Covid-19 Drug Molecule Developed by Hansraj College Researchers. Retrieved from https://duexpress.in/anti-covid-19-drug-moleculedeveloped-by-hansraj-college-researchers/.

Fehr, A. R. \& Perlman, S. (2015). Coronaviruses: an overview of their replication and pathogenesis. In H.J. Maier, E. Bickerton and P. Britton (eds.) Coronaviruses Methods and Protocols. Methods in Molecular Biology. Springer. 1282, (pp 1-23).

Guy, R. K., DiPaola, R. S., Romanelli, F. \& Dutch, R.E (2020). Rapid repurposing of drugs for COVID-19. Science. 368(6493), 829-830. doi:10.1126/science.abb9332.

Hoffmann, M., Kleine-Weber, H., Schroeder, S., Krüger, N., Herrler, T., Erichsen, S., Schiergens, T. S., Herrler, G., Wu, N., Nitsche, A., Müller, M. A., Drosten, C. 
\& Pöhlmann, S. (2020). SARS-CoV-2 Cell Entry Depends on ACE2 and TMPRSS2 and Is Blocked by a Clinically Proven Protease Inhibitor. Cell. 181(2), 271-280.

Kumar, S., Nyodu, R., Maurya, V. K. \& Saxena, S. K. (2020). Morphology, Genome Organization, Replication, and Pathogenesis of Severe Acute Respiratory Syndrome Coronavirus 2 (SARS-CoV-2). In S. K. Saxena (ed.). Coronavirus Disease 2019 (COVID-19) (pp 23-31). Singapore. Springer. https://doiorg/10.1007/978-981-15-4814-7.

Loutfy, M. R., Blatt, L. M., Siminovitch, K. A., Ward, S., Wolff, B., Lho, H., Pham, D. H., Deif, H., LaMere, E. A., Chang, M., Kain, K. C., Farcas, G. A., Ferguson, P., Latchford, M., Levy, G., Dennis, J. W., Lai, E. K. \& Fish, E. N. (2003). Interferon alfacon-1 plus corticosteroids in severe acute respiratory syndrome: a preliminary study. JAMA. 290(24), 3222-3228. doi: 10.1001/jama.290.24.3222. PMID: 14693875.

Lu, W., Xu, K. \& Sun, B. (2010). SARS Accessory Proteins ORF3a and 9b and Their Functional Analysis. In S.K. Lal (ed.) Molecular Biology of the SARSCoronavirus (pp 167-175). Heidelberg Dordrecht London New York. Springer . ISBN: 978-3-642-03682-8.

McKimm-Breschkin, J. (2012). Influenza neuraminidase inhibitors: Antiviral action and mechanisms of resistance. Influenza and Other Respiratory Viruses. 7(Suppl. 1), 25-36.

Perlman, S. \& Netland, J. (2009). Coronaviruses post-SARS: update on replication and pathogenesis. Nat. Rev. Microbiol. 7, 439-450. doi:10.1038/nrmicro2147.

Petrosillo, N., Viceconte, G., Ergonul, O., Ippolito, G. \& Petersen, E. (2020). COVID19, SARS and MERS: are they closely related? Clin Microbiol Infect. 26(6), 729734. doi:10.1016/j.cmi.2020.03.026. 
Qinfen, Z., Jinming, C., Xiaojun, H., Huanying, Z., Jicheng, H., Ling, F., Kunpeng, L., \& Jingqiang, Z. (2004). The life cycle of SARS coronavirus in Vero E6 cells. Journal of medical virology, 73(3), 332-337.

Saikatendu, K. S., Joseph, J. S., Subramanian, V., Clayton, T., Griffith, M., Moy, K., Velasquez, J., Neuman, B. W., Buchmeier, M. J., Stevens, R. C., \& Kuhn, P. (2005). Structural basis of severe acute respiratory syndrome coronavirus ADPribose-1"-phosphate dephosphorylation by a conserved domain of nsP3. Structure. 13, 1665-1667.

Saxena, S. K., Kumar, S., Maurya, V. K., Sharma, R., Dandu, H. R., \& Bhatt, M. (2020). Current Insight into the Novel Coronavirus Disease 2019 (COVID-19). Coronavirus Disease 2019 (COVID-19): Epidemiology, Pathogenesis, Diagnosis, and Therapeutics , 1-8. https://doi.org/10.1007/978-981-15-48147_1

Serrano, P., Johnson, M. A., Almeida, M. S., Horst, R., Herrmann, T., Joseph, J. S., Neuman, R. W., Subramanian, V., Saikatendu, K. S., Buchmeier, M. J., Stevens, R. C., Kuhn, P. \& Wuthrich, K. (2007). Nuclear magnetic resonance structure of the N-terminal domain of nonstructural protein 3 from the severe acute respiratory syndrome coronavirus. Journal of Virology. 81, 12049-12060. doi: 10.1128/JVI.00969-07.

Sharma, R., Agarwal, M., Gupta, M., Somendra, S., \& Saxena, S. K. (2020). Clinical Characteristics and Differential Clinical Diagnosis of Novel Coronavirus Disease 2019 (COVID-19). Coronavirus Disease 2019 (COVID-19): Epidemiology, Pathogenesis, Diagnosis, and Therapeutics , 55-70. https://doi.org/10.1007/978-981-15-4814-7_6

Shereen, M. A., Khan, S., Kazmi, A., Bashir, N. \& Siddique, R. (2020). COVID-19 infection: Origin, transmission, and characteristics of human coronaviruses. $J$. Advanced Research. 24, 91-98. doi:10.1016/j.jare. 
Shin, J. S., Jung, E., Kim, M., Baric, R. S. \& Go, Y. Y. (2018). Saracatinib Inhibits Middle East Respiratory Syndrome-Coronavirus Replication In Vitro. Viruses. 10(6), 283.

Shirato, K., Kawase, M. \& Matsuyama S. (2018). Wild-type human coronaviruses prefer cell-surface TMPRSS2 to endosomal cathepsins for cell entry. Virology. 517, 915 .

Song, Z., Xu, Y., Bao, L., Zhang, L., Yu, P., Qu, Y., Zhu, H., Zhao, W., Han, Y. \& Qin, C. (2019). From SARS to MERS, Thrusting Coronaviruses into the Spotlight. Viruses. 11(1), 59. doi: 10.3390/v11010059.

Sungnak, W., Huang, N., Bécavin, C., Berg, M. \& Network, H. (2020). SARS-CoV-2 entry genes are most highly expressed in nasal goblet and ciliated cells within human airways. Nature Medicine. 26, 681-687.

Tai, D. Y. (2007). Pharmacologic treatment of SARS: current knowledge and recommendations. Ann. Acad. Med. Singapore. 36(6), 438-443.

Yan, Y., Shin, W. I., Pang, Y. X., et al., (2020). The First 75 Days of Novel Coronavirus (SARS-CoV-2) Outbreak: Recent Advances, Prevention, and Treatment. Int. J. Environ. Res. Public Health. 17(7), 2323. doi:10.3390/ijerph17072323.

Zhang, H., Penninger, J. M., Li, Y., Zhong, N. \& Slutsky, A. S. (2020). Angiotensinconverting enzyme 2 (ACE2) as a SARS-CoV-2 receptor: molecular mechanisms and potential therapeutic target. Intensive Care Med. 46(4), 586590. doi:10.1007/s00134-020-05985-9.

How to cite this article: Goel, N., Ritika \& Kumari, S. (2020). Probable strategies to combat corona pandemic by tracing its re-emergence from SARS virus. Vantage: Journal of Thematic Analysis, 1(2): 21-45.

DOI: https://10.52253/vjta.2020.v01i02.04

(C) The Author(s) 2020.

This work is licensed under a Creative Commons Attribution 4.0 International License which permits its use, distribution and reproduction in any medium, provided the original work is cited.

Vantage: Journal of Thematic Analysis, 2020; 1(2): 21-45 